\title{
20
}

\section{Developing a New Activity: STUDENT APPROVED}

\author{
Julie Smit, Dora Cavallo-Medved, \& Kirsten Poling \\ University of Windsor
}

Do you have an idea for a new activity or laboratory exercise that you would like to incorporate into your course but feel unsure as to how it will be received by your students? This was our concern when developing first-year biology labs for a biology majors' course at University of Windsor. Through a Centred on Learning Innovation Fund (CLIF) grant at our institution, we were able to form new and revised laboratory exercises, incorporating on-line, active, and reflective components. But, would the students like the labs? Which labs should be replaced? Using student surveys and a 'trial' lab, we were able to collect information about the new lab, as well as the old labs. It was a revelation to witness the enthusiasm and the appreciation first-year students had for being involved in the development of the labs. The goal of this essay is to identify the benefits and costs of incorporating a new activity into a course, as well as describing the process that we developed, which includes student input as an important component in the development of the activity.

\section{Introduction}

$\mathrm{T}$ The implementation of a class activity can transform a classroom environment from a passive experience to one that is interactive, while still reinforcing student learning of relevant, and perhaps complex, subject areas. Active learning can take many forms, from a short in-class exercise, like minute papers and clicker questions, to a complete course activity, like problem-based learning and laboratory exercises (Cameron, 1999; Crawford, 2007). Independent of the type of activity implemented, allowing students to take part in their own learning provides the opportunity for a deeper learning expe- rience (Biggs, 2003).

Developing a new activity and incorporating it into a course and/or classroom requires time commitments by the instructor in determining areas of weakness and creating effective methods to improve the learning experience. In addition, instructors must be prepared to accept a loss of classroom control associated with the move from a teacher-centred to a student-centred environment. Indeed, common concerns associated with adding a novel activity to a course include difficulties relating to organizational and technical issues (e.g. in-class time commitment, 
new technology), as well as risks associated with student acceptance of a new learning experience (i.e. potential student anxiety, lack of interest). We experienced these same concerns when developing new laboratory activities for a first-year biology course. Personal communication with students, instructors, and laboratory personnel indicated that some of the laboratory exercises in the course were outdated and required improvement, so it was our aim to develop new exercises that students would find engaging and interesting while also improving comprehension of relevant course material.

The process we developed in our study focused on providing undergraduate students with opportunities to give their perceptions of current and newly developed lab activities through the use of surveys. Feedback has been identified as an important component for improvement of both undergraduate student learning (Chickering \& Gamson, 1987) and instructor teaching practices (Piccinin, 2006). In this case, we used the feedback from polled students before, during, and after implementing newly designed lab exercises so that we could be confident that the improvements to the laboratory sessions were aligned with the students' concerns and interests.

In this essay, we identify the advantages of implementing a new activity and areas of concern associated with this course of action, describe the process we used to develop and incorporate new laboratory activities into the first-year biology course, and discuss the applicability of this process to other situations. To this end, we have outlined the different phases of this new process for laboratory development, describing how student responses were used to assist in defining, shaping, and creating new laboratory exercises.

\section{Ranking of Laboratory Sessions}

As a first step to developing new lab exercises, it was necessary to identify laboratory sessions that students perceived as providing either a positive or negative experience. Although we were skeptical about student willingness to complete the 2008 survey, especially one containing both ranking (using a
Likert-scale with 'really disliked, disliked, OK, liked, and liked a lot' as the five ranks) and written portions, we were pleasantly surprised to find that of the $58 \%$ of the 258 students who completed the survey, $75 \%$ (217) provided written comments. We learned from both the rankings and student comments that students were particularly dissatisfied with two (of six) laboratory sessions, using words such as 'boring,' 'tedious,' and 'repetitive' to describe these labs. They requested more 'hands-on' labs, use of videos and/or demonstrations, and exercises that were not repeats of secondary school laboratory exercises. Based on these results, we identified one laboratory session for complete revision and two laboratory sessions that required additional hands-on activities.

\section{Developing and Experiencing the New 'First Lab'}

Just as the first lecture of a course sets the stage for all future lectures, the first laboratory session will have the same effect on future laboratory expectations. For this reason, we decided to assign the newly developed laboratory session as the introductory lab session of the course, ensuring a welcoming laboratory experience. Thus, we decided to develop laboratory activities for this new session that included an interactive web-based pre-lab component, a hands-on in-lab component (composed of various stations each with different activities), and a written component that required student interaction (in pairs/groups). Once the new laboratory activities were developed to form a laboratory session, volunteer students from the firstyear undergraduate biology course were recruited to perform a practice-run of this new session. Since these students had just completed the course, they were able to make a direct comparison between the current, less favourable laboratory session with the newly designed version. These volunteers were required to complete all components of the new laboratory session (pre-lab exercises, in-lab exercises, and assignments), as well as an in-lab survey, to record their experiences. The enthusiasm these students had for the project was apparent by 
the willingness of 36 of the 40 interested students to take part in the practice laboratory session even though it occurred approximately five weeks after the completion of course exams.

The positive results from the practice laboratory survey indicated that volunteers felt that the newly developed laboratory session provided a very positive learning environment. Overall, volunteers indicated that they found the group of new activities a great improvement over the 'old' laboratory activities, with $43 \%$ providing positive reviews of the pre-lab section (liking or really liking) and $70 \%$ providing positive reviews of the in-lab components. Other feedback included comments about instructions and procedures that required clarification and improvement.

\section{Surveying \& Incorporating the New 'First Lab' into the Course}

Based on the survey responses and in-lab studentstudent and student-faculty interactions during the practice laboratory session, changes were made to some of the laboratory exercises before incorporating them into the first-year biology course in the Fall 2009 term. These changes included removing one of the in-lab exercises due to time constraints and making minor changes to some of the lab protocols.

Students who completed the laboratory sessions in Fall 2009, which incorporated changes to a total of three laboratory sessions, were asked to complete a survey (similar to the Fall 2008
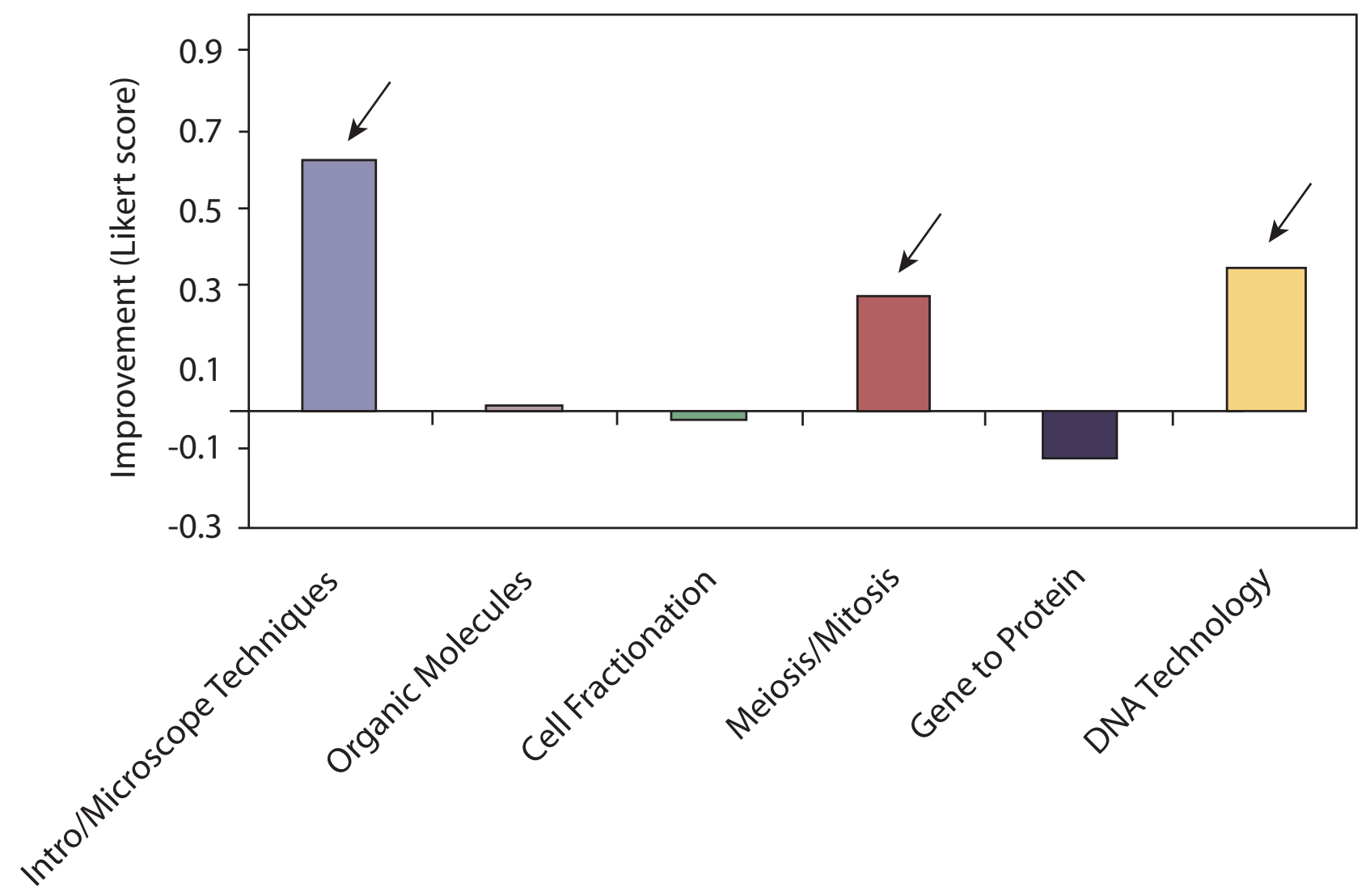

FIGURE 1

Levels of improvement for each of the weekly first year biology course laboratory experiences, based on a 5 level Likert ranking score. Arrows indicate the exercises that were modified from the previous year. 
survey above), providing their perceptions of their laboratory experience during the semester. Relative to the previous year, students polled (232) indicated an improvement in all of the laboratory sessions that had undergone changes, with the greatest level of improvement in the newly developed (first) laboratory session (see Figure 1), increasing more than 0.6 on the Likert scale. It should be noted that laboratory sessions that were not changed showed little difference in ranking relative to the previous year's survey, indicating that the positive increase in student satisfaction ranking with the new laboratory activities is not an artifact.

\section{Final Comments}

Our experience from this study indicates that undergraduate students appear to have an interest in being involved in the development of courses. We greatly appreciated the written comments on the survey forms as they were very informative, providing both positive and negative responses to the laboratory exercises as well as suggestions for further development of laboratory activities. The group of students who volunteered to participate in the practice laboratory session appeared to enjoy the experience. Some of them contacted us to indicate that they would be very interested in volunteering for any future studies in this area. One volunteer contacted us with the following message: I just wanted to let you know that I really enjoyed being a part of the enhancement of the first year biology lab! I really think it's a great way to give the students an opportunity to work along with their professor.

As a result of this process we developed, we were able to incorporate new laboratory activities into the first-year biology course with confidence that organizational and technical issues had been addressed and that students would find the laboratory activities interesting. It is our plan to continue to include undergraduate students in the development of biology laboratory activities. Our ongoing research into student-centred approaches to the development of laboratory exercises involves having undergraduate students create a laboratory exercise themselves, with guidance and supervision. Moreover, this process can be further explored and used when incorporating many different types of activities in lectures, laboratories, or distance courses. This will provide opportunities for engaging undergraduate students in course development, permitting them to be involved in their own learning.

\section{References}

Biggs, J.B. (2003). Teaching for quality learning at university (2nd ed). Berkshire: Open University Press.

Cameron, B.J. (1999). Active learning. Halifax: Society for Teaching and Learning in Higher Education.

Chickering, A.W. \& Gamson, Z.F. (1987). Seven principles for good practice in undergraduate education. AAHE Bulletin, 39(7), 3-7.

Crawford, I. (2007). Teaching for improved learning: Active learning. In K. Smith (Ed), Active learning in teaching, learning, assessing (pp. 83-89). Oakville: Mosaic Press.

Piccinin, S.J. (2006). Feedback: Key to learning. Halifax: Society for Teaching and Learning in Higher Education.

\section{Biographies}

Julie Smit is a Science Teaching and Learning Specialist in the Department of Biological Sciences at the University of Windsor. Her interests focus on improving student learning in both lecture and laboratory environments, primarily through the incorporation of active-learning techniques and technology.

Dora Cavallo-Medved is an Assistant Professor in the Department of Biological Sciences at the University of Windsor where her main focus is teaching the 
first-year biology courses for Science majors. She is interested in establishing novel teaching and learning strategies for undergraduate students and working with these students in curriculum development. In addition, she maintains an active scientific research program in the field of cancer biology and functional imaging of 3D cancer models.

Kirsten Poling is a Science Teaching and Learning Specialist in the Department of Biological Sciences at the University of Windsor. Her research interests lie in developing new techniques for engaging students in their academic pursuits and getting students to take responsibility for their performance in their coursework. In addition to the current work in using a student-centred approach for developing biology laboratory exercises, she has also conducted research using Tablet PC computers to enhance student engagement and to explore whether technology in the biology-specific classroom can enhance learning and retention of information, as well as increase interactions between students groups and the professor. 